\title{
“AUTOS DE RESISTÊNCIA" COMO INSTRUMENTO LEGITIMADOR DA POLÍTICA DE EXTERMÍNIO DOS “INDIGNOS DE VIDA"
}

\author{
"AUTOS DE RESISTÊNCIA" AS AN INSTRUMENT FOR EXTERMINATION POLICY \\ OF THE "ENEMY"
}

\author{
Larissa Leilane Fontes de Lima ${ }^{1}$ \\ Igor Frederico Fontes de Lima ${ }^{2}$
}

\begin{abstract}
RESUMO
O presente trabalho objetiva analisar, através do estudo dos "autos de resistência", suas tensões com a desigualdade social. Partindo do entendimento sobre os processos de criminalização através de uma perspectiva marxista - foi possível tecer algumas considerações acerca da construção social do "inimigo" para, então, entender como funcionam as políticas de extermínio desses setores da sociedade. As estruturas policiais, no contexto de "guerra às drogas", assumem um papel fundamental na política de extermínio dos "inimigos", a qual é viabilizada pelos "autos de resistência".
\end{abstract}

Palavras-chave: Criminologia crítica; Autos de resistência; Construção do inimigo; Guerra às drogas; Extermínio.

\begin{abstract}
The present article aims to analyze, through the study of "autos de resistência", its tensions with social inequality. From the understanding of the processes of criminalization - through a Marxist perspective - it was possible to make some observations about the social construction of the "enemy" to then understand how works the extermination policy of these sectors of society. The police structures in the Brazilian context of the "war on drugs", play a key role in the policy of extermination of the "enemy", which is made possible by the "autos de resistência".
\end{abstract}

Keywords: Critic criminology; Autos de resistência; consctruction of the enemy; War on drugs; Extermination.

\footnotetext{
${ }^{1}$ Mestranda em Direito (UFRJ), bolsista CAPES, pesquisadora do Laboratório de Direitos Humanos (LADIH) da UFRJ, vinculada ao "Grupo de Pesquisas Drogas e Direitos Humanos" (CNPQ). Rio de Janeiro (Brasil). E-mail: lari-fontes@hotmail.com

${ }^{2}$ Mestrando em Direito (UNIT), bolsista CAPES, membro do Projeto "Caracterização de mortes violentas em municípios sergipanos: perfil sócio-econômico dos envolvidos, aspectos situacionais e informações sobre os crimes”, financiado pela FAPITEC/SE. Sergipe (Brasil).
} 


\section{INTRODUÇÃO}

Apesar dos padrões de condutas variarem de acordo com as diversas sociedades, há algo em comum entre elas: o desafio de conviver com o diferente. Ocorre, portanto, uma divisão entre os indivíduos que atendem aos requisitos para receber tratamento de cidadão e aqueles que não atendem. Estes passam a ser vistos como "diferentes", "os outros", "estranhos", ou simplesmente “inimigos”. É por serem vistos como "inimigos" que a sociedade agirá a fím de exterminá-lo.

A questão criminal, pensada a partir de um olhar marxista, que a associa as relações entre o capital e o trabalho vivo, passando da fenomenologia criminal para os processos de criminalização, ao deslocar-se do estudo das causas para o estudo dos mecanismos de construção da realidade social, denuncia artifícios desleais dos quais o Estado se vale para exercer o controle social. Tal deslocamento só se torna possível a partir do entendimento da luta de classes por trás da criminalização. Surge, assim, a criminologia crítica.

A partir dessa perspectiva marxista, poderemos compreender os processos de formação e de aniquilação da figura do inimigo, contextualizando aos dias atuais, em que a "guerra às drogas" figura como a principal justificativa para que o sistema penal, "em nome da proteção à vida", abra caminho para violações de direitos fundamentais. O caráter político do poder punitivo brasileiro denuncia a existência de uma pena de morte informal no ordenamento jurídico, que legitima a produção de verdadeiros massacres.

Os “autos de resistência" configuram um desses mecanismos - senão o principal - e atuam como um dos principais legitimadores do modelo militarizado das polícias no Estado de Direito. $\mathrm{Na}$ medida em que provoca o anseio social por segurança, o medo enquanto sentimento coletivo dos "cidadãos de bem" autoriza a eliminação do "inimigo" do convívio social, e é a polícia (principalmente a militar) quem vai garantir essa "segurança".

O objetivo geral é a desconstrução dos modelos tradicionais de se pensar a questão criminal e o punitivismo, o qual possibilitará os objetivos específicos, que se referem à análise de situações práticas - principalmente referentes à "guerra às drogas" - a fim de entender como o sistema penal oferece instrumentos para o extermínio da população negra e pobre e como os meios de comunicação e o próprio Poder Judiciário colaboram com a legitimação das políticas de extermínio através da segurança pública militarizada.

Sendo assim, o presente trabalho mostra-se um título passível de debates no âmbito social, cultural e jurídico a fim de um maior esclarecimento e aprofundamento a seu respeito na tentativa de uma melhor compreensão, criando, posteriormente, a capacidade de se tecer críticas 
a seu respeito, demonstrando-se sua relevância nas esferas científica, social e jurídica, onde restará aumentado o acesso à informação para acadêmicos e para a população como um todo, a respeito de uma questão urgente, atual e real que precisa ser amplamente divulgada.

A metodologia de abordagem adotada para elaboração do presente trabalho é o método dialético, uma vez que se trata de um método de investigação dinâmica e totalizante da realidade pelo estudo de sua ação recíproca, da contradição inerente ao fenômeno. Tal método admite que os fatos devem ser considerados dentro do contexto social, político, econômico e cultural.

A metodologia de procedimento adotada é o método comparativo, que consiste na verificação da compatibilidade vertical dos "Autos de Resistência" à Constituição Federal e à Legislação Infraconstitucional, num estudo descritivo e análise dos elementos de estrutura, apontando vínculos entre elementos presentes e ausentes.

A técnica de pesquisa adotada no presente trabalho é a bibliográfica, tendo em vista que, para o embasamento teórico, foram utilizadas fontes de pesquisa desenvolvida a partir de material já elaborado, principalmente livros e artigos jurídicos pertinentes, legislação, publicação de periódicos e impressos diversos, abordando-os de maneira qualitativa, e assim, analisando e interpretando os diversos posicionamentos acerca do tema, para, por fim, se chegar a uma solução ao problema apresentado. Ainda, qualquer documentação indireta de relevância jurídica, assim como pesquisa em documentos eletrônicos, numa proposta de leitura seletiva, reflexiva, crítica e analítica.

\section{UMA PERSPECTIVA MARXISTA ACERCA DA QUESTÃO CRIMINAL}

Apesar de Karl Marx não ter desenvolvido pensamentos articulados acerca da questão criminal, ele apontou o sentido classista das criminalizações históricas e do poder punitivo. A luta de classes estabeleceu uma crescente conflitividade social com a finalidade de que alguns se apropriassem dos corpos e dos tempos dos outros. Ao mesmo tempo, surgem várias formas de controle social para dar conta dessa captura, e elas variam desde a educação ao sistema penal (BATISTA, 2011, p. 79).

A "nova criminologia" ou "criminologia crítica" provocou uma mudança de paradigma, que deslocou-se da abordagem do autor, das condições subjetivas que levam alguém a cometer crimes, para a abordagem das condições objetivas, estruturais e institucionais da sociedade 
capitalista, através das quais é construída a "realidade social" do desvio, ou seja, para os mecanismos através dos quais são criados os processos de criminalização (BARATTA, 2002, p. 160). No mesmo sentido, Orlando Zaccone:

\begin{abstract}
Os estudiosos do fenômeno da deslegitimação do sistema penal e do desprestígio dos discursos jurídico-penais, no entanto, são inânimes em admitir que, embora diferentes dimensões analíticas tenham participado desse movimento critico, a crise do discurso jurídico-penal foi obra, principalmente, do saber sociológico, que culminou na mudança do paradigma criminológico realizado pelas "teorias da reação social" ou lebelling approach, que operou "uma revolução científica no âmbito da sociologia criminal" (FILHO, 2007, p. 41)
\end{abstract}

Segundo Karl Marx (1998, p. 20), é na vida real que começa a ciência. Baratta corrobora o entendimento marxista e, portanto, propõe a recuperação da dimensão macrossociológica para a interpretação crítica dos fenômenos estudados pela criminologia. Assim, somente com base no contexto do objeto da sociologia geral pode-se construir um discurso baseado em dados empiricamente controláveis, em pesquisas bem localizadas, em metodologias previamente declaradas e experimentadas, e acompanhado, frequentemente, da consciência de sua função crítica em face das ideologias e, em geral, da realidade social dos fatos estudados (BARATTA, 2002, p. 26).

Corroboramos o entendimento marxista de que o crime não é ontológico e entendemos, portanto, que existe um processo de criminalização, que seleciona quem será rotulado enquanto criminoso de acordo com o bem que se interessa proteger. Para Alessandro Baratta, não há como compreender a criminalidade se não se estudar a ação do sistema penal:

\footnotetext{
(...) o status social de delinquente pressupõe, necessariamente, o efeito da atividade das instâncias oficiais de controle social da delinquência, enquanto não adquire esse status aquele que, apesar de ter realizado o mesmo comportamento punível, não é alcançado, todavia, pela ação daquelas instâncias. Portanto, este não é considerado e "tratado" como delinquente. (BARATTA, 2002, p. 86)
}

O direito penal, de acordo com a perspectiva marxista, surge como um discurso de classe utilizado para legitimar a hegemonia do capital e denuncia que os processos de criminalização são guiados pelo princípio da seletividade do sistema penal (BATISTA, 2011, p. 89). Essa constatação só pôde ser feita pela observação através do pensamento marxista, que foi o eixo fundamental para o surgimento de um olhar desconstrutor sobre as "verdades" jurídico-penais do iluminismo (BATISTA, 2011, p. 79). 
Para Vera (2011, p. 80), "não é à toa que, apesar da criminalização de algumas substâncias, o maior indicador criminal continua sendo o das infrações envolvendo a propriedade privada". Para Marx (2006, p. 102), somente a propriedade privada pode exercer o seu pleno domínio sobre o homem e tornar-se, na sua forma mais universal, um poder histórico-mundial. Assim, fica clara a linha que pretendemos seguir, de que por trás da questão criminal estão as relações de força e de poder.

Não há como compreender a construção social da figura do "inimigo" sem a consciência da luta de classes que existe por trás dos processos de criminalização. A crítica se dirige ao mito do direito penal como direito igual. (BARATTA, 2012, p.161). É necessário, portanto, que se tenha consciência dos métodos dos quais o Estado se vale para conseguir a legitimação da sociedade para fazer uso dos instrumentos necessários para tal. É necessário, ainda, termos consciência de que a seletividade do sistema penal atende aos interesses de uma hegemonia conservadora dominante.

Sendo o Estado, portanto, a forma pela qual os indivíduos de uma classe dominante fazem valer seus interesses comuns e na qual se resume toda a sociedade civil de uma época, conclui-se que todas as instituições comuns passam pela mediação do Estado e recebem uma forma política. [...] Daí, a ilusão de que a lei repousa na vontade e, mais ainda, em uma vontade livre, destacada da sua base concreta. (ENGELS; MARX, 1998, p.74)

O processo de criminalização é didaticamente dividido em três etapas, quais sejam: a criminalização primária; a criminalização secundária e o mecanismo de execução das penas ou das medidas de segurança. A criminalização primária nada mais é do que o mecanismo de produção de normas; a criminalização secundária diz respeito ao processo penal, que envolve o mecanismo de aplicação das normas através da ação dos órgãos de investigação e culmina com o juízo. (BARATTA, 2002, p.162).

É na aplicação das normas que visualizamos mais nitidamente seu destinatário préselecionado. As maiores chances de ser selecionado para fazer parte da "população criminosa" aparecem concentradas nos níveis mais baixos da escala social, Fatos que na criminologia tradicional são apontados como causas de criminalidade são, segundo a perspectiva marxista, bases sobre as quais o status de criminoso é atribuído. (BARATTA, 2002, p. 165)

Pavarini (2012, p. 204 - 205) também alerta sobre a natureza simbólica e a consequente eficácia estigmatizante da censura penal. Para ele, tais funções, juntamente à função de prevenção geral, são atributos exclusivos do Direito Penal "clássico", isto é, do Direito Penal que criminaliza condutas socialmente sentidas como merecedoras de pena, e que pune os autores 
reconhecendo-os e, portanto, estigmatizando-os como pertencentes ao que o autor convencionou chamar de classes perigosas. (BOITEUX; LIMA, 2016, no prelo)

O processo de criminalização parece ser, portanto, nada mais do que uma artifício do qual se vale o Estado a fim de estigmatizar a figura do criminoso, legitimando o seu extermínio do convívio social. O encarceramento e os assassinatos em massa praticados pela polícia são instrumentos desse processo de criminalização. Ocorre que esses assassinatos, por estarem cobertos pelo manto da "legítima defesa" e pelo "estrito cumprimento do dever legal", sequer são considerados homicídios. Os "autos de resistência" são uma verdadeira afronta aos Direitos Humanos.

\section{O INIMIGO SOCIALMENTE FORJADO}

É a retirada de direitos que possibilita o tratamento desumano. No entanto, essa situação não é assumida ou declarada pelo direito. Ela se exterioriza através das relações de poder e encontra legitimação no discurso criado pela ideologia dominante, que rotula de acordo com seus interesses. Para Zaffaroni (2007, p. 22), o hostis judicatus, do direito romano, era assim declarado para ser submetido a penas que eram vedadas a cidadãos. Numa situação excepcional, o Senado podia declarar pessoas como inimigos públicos, como hostis. Essa excepcionalidade ocorria quando os poderes políticos achavam que um cidadão romano ameaçava a segurança da República (LIMA; REGINATO, 2016, no prelo)

\footnotetext{
O inimigo declarado (hostis judicatus) configura o núcleo do tronco dos dissidentes ou inimigos abertos do poder de plantão, do qual participarão os inimigos políticos puros de todos os tempos. Trata-se de inimigos declarados, não porque declarem ou manifestem sua animosidade, mas sim por que o poder os declara como tais: não se declaram a si mesmos, mas antes são declarados pelo poder. A instituição do hostis judicatus romano cumpria a função de deixar o cidadão em condição semelhante à do escravo, para tornar-lhes aplicáveis as penas que eram vedadas para os cidadãos. A subtração à condenação judicial mediante expatriação fazia cessar automaticamente também a condição de cidadão. (ZAFFARONI, 2007, p. 23)
}

Pensar em "inimigo" pressupõe o status de guerra. Atualmente, no Brasil, vivenciamos a chamada "guerra às drogas". As aspas se devem ao fato de que esta é uma guerra convenientemente declarada por aqueles que detêm o poder. O contexto de guerra permite que o Estado se valha de mecanismos característicos de regimes totalitários, configurando o que Giorgio Agamben (2004, p. 13) convencionou chamar de estado de exceção. Para Agamben, o 
estado de exceção se apresenta como uma técnica caracterizada pela suspensão total ou parcial de direitos e garantias fundamentais para resolver problemas graves e situações emergenciais.

Essa técnica da qual o Estado se utiliza permite que o sistema penal elimine do convívio social, seja através do encarceramento ou de verdadeiros massacres, a figura do inimigo. No mesmo sentido, Orlando Zaccone:

O papel desempenhado pelo direito penal no controle social é distorcido pela dogmática que confere ao Estado, com exclusividade, o direito de punir. A lição é curta e simples: a norma penal incriminadora cria para o Estado, seu único titular, o direito de punir, configurando crime o exercício arbitrário das próprias razões, conforme previsto no Código Penal Brasileiro. (FILHO, 2007, p. 28)

Zygmunt Bauman (1998, p. 27), a partir de ideias de segurança e ordem como pilares das sociedades modernas, entende os "estranhos" como indivíduos que não reproduzem os padrões de comportamento previamente formulados por determinados meios sociais. O Estado moderno - responsável por criar seus estranhos - tomava para si a tarefa de aniquilá-los. Por gerar incertezas à ordem, a sociedade negava o diferente. Essa negação tem como elementos a dureza de um Estado arrogante cuja característica da empreitada aniquiladora aos estranhos era o uso da força (LIMA; REGINATO, 2016, no prelo).

Os cidadãos que eventualmente cometem crimes têm negada sua condição de seres humanos (Zaffaroni, 2007, pp.11-12). Num estado constitucional de direito - caso do Brasil -, essa é uma característica ainda mais contraditória. O "estranho", assim entendido como o indivíduo que diverge das direções políticas, bem como as pessoas que por não obedecerem a determinados padrões - que conotam a ideia de "sujeira" -, deixam de ser vistos como cidadãos ou cidadãs. A utilização do estado de exceção característica de regimes ditatoriais viabiliza a aniquilação desses estranhos, a "colocação em ordem" da sociedade. O estado de exceção pode ser verificado também em Estados Democráticos ou Constitucionais (AGAMBEN, 2004, p. 1213).

Essa relação se observa pela autorização do extermínio desses segmentos que não se encaixam no patamar de "aceitos" (BATISTA, 2003, p. 78 - 79). Com a utilização dessas técnicas que buscam o extermínio para garantir a "pureza" e a "higiene", o sofrimento físico e a violência passam a figurar não apenas nos regimes totalitários.

Estigmatizar setores da população enquanto "criminosos perigosos" é uma das técnicas da qual se vale o Estado na construção da figura do inimigo exterminável. Na Constituição Federal do Brasil, a única hipótese de extradição de brasileiro naturalizado é quando ele está 
envolvido com tráfico internacional de $\operatorname{drogas}^{3}$ (RODRIGUES; LIMA, 2016, no prelo). Este entendimento é corroborado por Nils Christie, que entende que:

Um inimigo doce e pacífico não é um bom inimigo. Mau e perigoso é o que o inimigo deve ser; e forte. Forte o suficiente para render honras e deferência ao herói que retorna para casa da guerra. Mas não tão forte que impeça o herói de retornar.O retrato do inimigo é um importante elemento na preparação para a guerra. (CHISTIE, 2011, p. 69)

\section{No mesmo sentilo, Lola Anyar de Castro:}

Na sociedade, existem vários estereótipos: o do alcoólatra, que seria um maltrapilho embrutecido pela bebida e deve, portanto, ser objeto de medidas violentas, ou sanções médicas, psiquiátricas e legais, cujo estereótipo serve para justificar a existência e o comportamento - agressivo e impune - dos alcoólatras das classes média e superior. O estereótipo do jovem hippie, drogado, sujo e amoral, serve para justificar à "gente de bem" burguesa a sua repressão contra os grupos de jovens politizados, considerados perigosos para as classes no poder. Ainda assim, a imagem do ladrão refere-se de preferência ao do pequeno assaltante e se contrapõe à do especulador, cujo comportamento acaba ratificado pela admiração e o êxito (...) $\mathrm{O}$ criminoso estereotipado é, pois, função do sistema estratificado e concorre para mantê-lo inalterado. Isto permite à maioria não criminosa, redefinir-se com base nas normas que aquele violou e reforçar o sistema de valores de seu próprio grupo. (CASTRO, p. 126)

Sob a justificativa de ser a "guerra às drogas" uma questão de saúde pública, o traficante de drogas é considerado um dos criminosos mais perigosos do ambiente social (RODRIGUES; LIMA, 2016, no prelo). Um sistema que deveria ser baseado em evidências de danos e riscos à saúde, ao contrário, de acordo com o modelo proibicionista, se funda em preconceitos e presunções pouco afeitas a questionamentos e verificações concretas:

Na realidade, a estratégia proibicionista baseia-se na imposição de controle penal sobre o uso e a venda de drogas rotuladas como ilícitas, por meio de um discurso moralista, baseado na alegada necessidade de proteção da saúde pública. Tal distinção entre drogas lícitas e ilícitas se deu por pura conveniência política, sem avaliação empírica ou científica dos riscos de cada substância a ser controlada. (RODRIGUES, 2015)

\footnotetext{
${ }^{3}$ Art. $5^{\circ}$ Todos são iguais perante a lei, sem distinção de qualquer natureza, garantindo-se aos brasileiros e aos estrangeiros residentes no País a inviolabilidade do direito à vida, à liberdade, à igualdade, à segurança e à propriedade, nos termos seguintes:

$[\ldots]$

LI - nenhum brasileiro será extraditado, salvo o naturalizado, em caso de crime comum, praticado antes da naturalização, ou de comprovado envolvimento em tráfico ilícito de entorpecentes e drogas afins, na forma da lei; (BRASIL. Constituição. Constituição da República Federativa do Brasil. Brasília, DF, Senado, 1998)
} 
Segundo Nilo Batista, a atual política criminal da "guerra contra às drogas" ofende mais à saúde pública que à própria circulação das substâncias entorpecentes tidas como ilícitas. O autor questiona:

Se é verdade que o direito busca, ao reprimir as condutas descritas como tráfico de drogas, proteger "o estado em que o organismo social exerce normalmente todas as suas funções" (saúde pública), como entender que a violência criada pela guerra contra o tráfico no Rio de Janeiro tenha atingido níveis de homicídios superior aos da guerra de Bush no Iraque? (BATISTA, 1998, p. 90)

A "guerra às drogas" é, em verdade, uma guerra aos traficantes de drogas - aqueles estigmatizados enquanto criminosos perigosos - e ela mata mais do que o uso das drogas ilícitas (RODRIGUES; LIMA, 2016, no prelo). Alguns dados extraídos de um relatório publicado pela Anistia Internacional ${ }^{4}$ em 3 de agosto de 2015 evidenciam a estratégia proibicionista, dentre eles, o fato de que em dez anos (de 2005 a 2014), foram registrados 8.466 (oito mil, quatrocentos e sessenta e seis) casos de homicídios decorrentes de intervenção policial no estado do Rio de Janeiro, sendo que, desses, 5.132 (cinco mil, cento e trinta e dois) ocorreram na cidade do Rio de Janeiro; e o fato de que a grande maioria dessas ocorrências concentra-se nas áreas mais pobres da cidade, nas zonas norte e oeste, tendo como vítimas, consequentemente, em sua imensa maioria, jovens negros.

No atual estágio do capitalismo o tratamento desumano dado às camadas sociais escolhidas a fazer parte do sistema penal, é um emblema da construção e aniquilação do inimigo na história da humanidade. Ao institucionalizar essa intolerância o Direito Penal passa a ser o maior instrumento legal para colocar em prática uma política higienista através, dentre outros elementos, da seletividade penal (LIMA; REGINATO, 2016, no prelo).

A seletividade é, portanto, a função real e a lógica estrutural de funcionamento do sistema penal, comum às sociedades capitalistas patriarcais. E nada simboliza melhor a seletividade do que a clientela da prisão, ao revelar que a construção (instrumental e simbólica da criminalidade - a criminalização - incide seletiva e de modo estigmatizante sobre a pobreza e a exclusão social, majoritariamente de cor não branca e masculina, e apenas residualmente (embora de forma crescente) feminina. (ANDRADE, 2012, pp. 137-138)

\section{O PAPEL DOS "AUTOS DE RESISTENCIA" NA ANIQUILAÇÃO DO "INIMIGO"}

\footnotetext{
${ }^{4}$ A anistia Internacional é um movimento mundial com mais de 7 milhões de apoiadores, membros e ativistas, em mais de 160 países e territórios, que faz campanhas para acabar com os mais graves abusos dos direitos humanos, independente de quaisquer governos, ideologias políticas e interesses econômicos ou religiões, sendo financiados, sobretudo, por doações individuais. (ANISTIA INTERNACIONAL, 2015)
} 
Para que possamos entender como funciona o instituto dos "autos de resistência", é necessário sabermos que, via de regra, quando o agente pratica uma conduta típica esta será também antijurídica. Entretanto, há ações típicas que:

Pela posição particular em que se encontra o agente ao praticá-las, se apresentam em face do Direito como lícitas. Essas condições especiais em que o agente atua impedem que elas venham a ser antijurídicas. São situações de excepcional ilicitude que constituem as chamadas causas de exclusão da antijuridicidade, justificativas ou descriminantes. (BRUNO, 1967 apud GRECO, 2009. p. 316)

O Código Penal de 1940 cuidou de elencar em seu artigo $23^{5}$, em rol taxativo, as causas excludentes de ilicitude. A definição legal de legítima defesa ficou a cargo do artigo 25 do mesmo diploma. Vejamos:

Art. 25 - Entende-se em legítima defesa quem, usando moderadamente dos meios necessários, repele injusta agressão, atual ou iminente, a direito seu ou de outrem. (CÓDIGO PENAL, 1940)

Os "autos de resistência" surgiram no contexto da ditadura militar, como uma medida administrativa que tinha o escopo de absolver, antes mesmo de qualquer julgamento, o policial que praticasse os crimes de lesão corporal ou homicídio amparados pela excludente de ilicitude, no caso, o já conceituado instituto da legítima defesa.

Durante a realização de uma pesquisa em três delegacias distritais da zona norte da cidade do Rio de Janeiro, em 2008, no âmbito do estudo "O inquérito policial no Brasil: uma pesquisa empírica", sob coordenação do Prof. Michel Misse, alguns aspectos sobre determinados Inquéritos Policiais chamaram sua atenção. Notou-se que parte significativa daqueles Inquéritos era classificada como "Auto de Resistência" e se diferenciava em alguns aspectos dos homicídios dolosos de um modo geral.

Primeiramente, constatou Misse, tal diferenciação se dá porque, em sua maioria, são homicídios cometidos por um operador policial, em serviço (geralmente um policial militar, mas também ocorrem casos com policiais civis). Em seguida, porque se trata de uma morte com autoria esclarecida desde o começo, já que são os próprios policiais que informam a ocorrência, alegando, contudo, terem agido sob o amparo do instituto da legítima defesa. (MISSE, 2010)

Tal alegação, desde que comprovada, retira a ilicitude do fato, como já esclarecido. Logo, o policial não terá praticado crime algum. Ocorre que, na realidade, sequer investiga-se a alegação do policial, procedendo-se imediatamente ao arquivamento dos "autos de resistência"

5 Art. 23 - Não há crime quando o agente pratica o fato: I - em estado de necessidade; II - em legítima defesa; III - em estrito cumprimento de dever legal ou no exercício regular de direito. 
por parte do Ministério Público. O pesquisador observou, ainda, que também era marcante a ausência sistemática de testemunhas - que não os próprios policiais envolvidos no evento, a ausência de perícias no local e de outras diligências para se apurar a dinâmica dos fatos.

Tais constatações nos levam a uma outra, ainda mais grave: no Brasil, 99\% dos "autos de resistência" são arquivados sem investigação. Trata-se, portanto, de uma ocorrência policial com autoria definida desde o Registro da Ocorrência e arquivada antes mesmo de ser investigada. (MISSE, 2013)

O instrumento "auto de resistência"6 funciona como um documento capaz de registrar uma atuação estatal legítima de utilização da força (Artigo 292 do Código de Processo Penal), nos casos em que alguém se oponha à execução de ato legal, mediante violência ou ameaça a funcionário competente para executá-lo (Artigo 329 do Código Penal). A recente Resolução no 2, de 13 de outubro de 2015, conjunta do Conselho Superior da Polícia e do Conselho Nacional dos Chefes da Polícia Civil, publicada no Diário Oficial da União no dia 4 de janeiro de 2016, aboliu o uso dos termos "autos de resistência" e "resistência seguida de morte". A partir de então, as ocorrências passam a ser registradas como "lesão corporal decorrente de oposição à intervenção policial" ou "homicídio decorrente de oposição à ação policial".

É importante atentarmos para o fato de que a forma jurídica da letalidade estatal pode ser tão violenta quanto um disparo de fuzil (FILHO, 2015). Para Orlando Zaccone, existe uma relação entre as palavras e os cadáveres, remontando ao conceito de Zaffaroni de "linguagem mortífera”. O que ambos quiseram dizer com isso é que existem discursos reproduzidos propositadamente pelos detentores de poder que visam legitimar certas políticas de extermínio.

Os "autos de resistência" configuram um exemplo perfeito dessas palavras que matam. Isto porque seja nas decisões de arquivamentos ou na maneira como os meios de comunicação noticiam homicídios praticados por policiais, podemos perceber a forma como esses discursos são conduzidos de modo a exercer influência sobre a subjetividade dos indivíduos, a fim de aliená-los para que eles legitimem a atuação estatal no sentido de exterminar o "inimigo".

${ }^{6} \mathrm{O}$ conceito de "auto de resistência" neste artigo utilizado foi extraído da dissertação de mestrado de Sylvia Amanda da Silva Leandro, apresentada ao Programa de Pós-graduação em Direito da Faculdade Nacional de Direito da Universidade Federal do Rio de Janeiro, como requisito parcial à obtenção do título de Mestre em Direito. A recente Resolução ${ }^{\circ}$ 2, de 13 de outubro de 2015, conjunta do Conselho Superior da Polícia e do Conselho Nacional dos Chefes da Polícia Civil, publicada no Diário Oficial da União no dia 4 de janeiro de 2016, aboliu o uso dos termos "autos de resistência" e "resistência seguida de morte". A partir de então, as ocorrências passam a ser registradas como "lesão corporal decorrente de oposição à intervenção policial" ou "homicídio decorrente de oposição à ação policial". 
Vejamos um exemplo de decisão de arquivamento de "auto de resistência" em que fica bem clara a afirmativa supra:

\begin{abstract}
"Quando Marcos Antônio recebeu voz de assalto emitida pelos agentes, saiu do carro em que estava, deu ordem de parada aos assaltantes e recebeu tiros, mas, em revide, contra eles atirou, matando, infelizmente, somente Antônio. O agente, portanto, matou um fauno, que objetivava cometer um assalto contra ele, agindo absolutamente dentro da lei. [...] Ressalto que, para desgosto dos defensores dos Direitos Humanos de plantão, não há dúvidas da tipificação da causa de exclusão da ilicitude em comento. [...] Bandido que dá tiro para matar tem que tomar tiro para morrer. Lamento, todavia, que tenha sido apenas um dos rapinantes enviado para o inferno. Fica aqui o conselho para Marcos Antônio: melhore sua mira. [...] Com efeito, a dinâmica dos fatos aqui estudados, leva à conclusão que o presente caderno investigatório somente foi distribuído para este Tribunal do Júri em razão de ter Antônio Rogério da Silva Sena, para a fortuna da sociedade, sido morto". (ZAGALLO apud FILHO, 2015, p. 37)
\end{abstract}

É importante atentarmos para o fato de que, quando se descobre que as vítimas de homicídios praticados por policiais têm em suas fichas criminais alguma "passagem" pela ou condenação no tráfico de drogas, os "autos de resistência" são, muitas vezes, arquivados. O traficante de drogas estigmatizado (preto, pobre, favelado) é, nas palavras de Orlando Zaccone, um verdadeiro passe livre para as ações policiais genocidas (FILHO, 2007, p. 58).

Além dos discursos judiciais, o modo como são noticiados esses homicídios também nos dizem muito sobre o processo social de construção do inimigo e legitimação de sua aniquilação. Um caso bastante conhecido de "autos de resistência" é o da juíza Patrícia Acioli, assassinada por um grupo de Policiais Militares em represália à sua atuação enquanto magistrada. Sylvia Leandro da Silva (2012), em sua dissertação de mestrado, bem observou que tal caso obteve grande repercussão na mídia - diferentemente da maioria esmagadora de casos de "autos de resistência" - por se tratar de uma juíza de direito. Essa observação reforça os argumentos apresentados no presente trabalho de que a criminalização recai sobre indivíduos, e não sobre atos, pois, quando o homicídio não recai sobre a figura típica do "inimigo", ele ganha repercussão. No mesmo sentido, Nils Christie:

Atos não são, eles se tornam; seus significados são criados no momento em que ocorrem. Avaliar e classificar são atividades essenciais aos seres humanos. O mundo nos vem na forma em que o constituímos. O crime, portanto, é o produto de processos culturais, sociais e mentais. Para todas as condutas, inclusive aquelas tidas como indesejáveis, há dúzias de alternativas possíveis para sua compreensão: perversidade, loucura, honra distorcida, ímpeto juvenil, heroísmo político - ou crime. As "mesmas" condutas podem, pois, ser tratadas por vários sistemas paralelos, como o judicial, o psiquiátrico, o pedagógico, o teológico. (CHRISTIE, 2011, p. 30). 


\section{CONCLUSÃO}

A partir da perspectiva marxista acerca da questão criminal, o presente artigo trabalhou com o estudo de alguns mecanismos de construção social relativos aos processos de criminalização. Essa mudança de perspectiva permitiu a visualização de fatores importantes da construção da figura do "inimigo matável”, com enfoque maior à utilização do instituto dos "autos de resistência" como mecanismo de controle social no contexto da "guerra às drogas".

No Brasil, o que legitima a prática de um homicídio não são as condições em que o fato ocorreu, mas sim as condições da pessoa que foi morta, que sequer podemos chamar de cidadão, pois é completamente marginalizada pela própria sociedade, que reforça e coloca os criminosos abaixo da condição de pessoa humana, retirando-lhes qualquer garantia de dignidade, dentre outros direitos fundamentais, a exemplo do direito à vida. Fato este que é rotineiramente reafirmado pela máxima "bandido bom é bandido morto".

Assim, a conclusão à qual chegamos foi a de que a "guerra às drogas" mata mais do que o próprio consumo das drogas e o legalismo autoritário (caráter político das decisões judiciais) guia as decisões no sistema penal brasileiro, ignorando a realidade fática para possibilitar a aplicação à realidade construída, denotando a conduta colaborativa com a política de extermínio do "inimigo".

\section{REFERÊNCIAS}

ANISTIA INTERNACIONAL. Você matou meu filho!: homicídios cometidos pela polícia militar na cidade do Rio de Janeiro. Rio de Janeiro: Anistia Internacional, 2015. Disponível em: < https://anistia.org.br/direitos-humanos/publicacoes/voce-matou-meu-filho/>. Acesso em: 18 de agosto de 2016.

AGAMBEN, Giorgio. Estado de Exceção. Tradução de Iraci D. Poleti. São Paulo: Boitempo, 2004.

BARATTA, Alessandro. Criminologia Crítica e Crítica do Direito Penal: introdução à sociologia do direito penal. Tradução de Juarez Cirino dos Santos. 3. Ed. Rio de Janeiro: Editora Revan: Instituto Carioca de Criminologia, 2002. 
BATISTA, Nilo. Introdução crítica ao direito penal brasileiro. Rio de Janeiro: Revan, 1999.

BATISTA, Vera Malaguti. Introdução crítica à criminologia brasileira. Rio de Janeiro: Revan, 2011, 2.ed. $128 \mathrm{p}$.

BATISTA, Vera Malaguti. O medo na cidade do Rio de Janeiro: dois tempos de uma história. Rio de Janeiro: Revan, 2003. 272 p.

BAUMAN, Zygmunt. O mal-estar da pós-modernidade. Rio de Janeiro: Zahar, 1998.

BRASIL. Código Penal. Decreto-Lei no 2.848 , de 7 de dezembro de 1940. Vade mecum. São Paulo: Saraiva, 2008.

BRASIL. Resolução no 2, de 13 de outubro de 2015. Conselho Superior da Polícia; Conselho Nacional dos Chefes da Polícia Civil. Secretaria de Direitos Humanos da Presidência da República. Publicação no Diário Oficial da União em 04 de janeiro de 2016. Disponível em: < http://pesquisa.in.gov.br/imprensa/jsp/visualiza/index.jsp?jornal=1\&pagina=8\&data=04/01/2016 >. Acesso em: 14 de agosto de 2016.

CASTRO, Lola Anyar de. Criminologia da reação social. Rio de Janeiro: Forense, 1983

CHRISTIE, Nils. Uma quantidade razoável de cime. Traduzido por André Nascimento. Rio de Janeiro. Revan, 2011.

D'Ellia Filho, Orlando Zaccone. Acionistas do nada: quem são os traficantes de drogas. Rio de Janeiro: Revan, 2007, 140 p.

D'Ellia Filho, Orlando Zaccone. Indignos de Vida: a forma jurídica da política de extermínio de inimigos na cidade do Rio de Janeiro. Rio de Janeiro: Revan, 2015. 278 p.

GRECO, Rogério. Curso de Direito Penal. 11. ed. Rio de Janeiro: Impetus, 2009

LEANDRO. Sylvia Amanda da Silva. O que matar (não) quer dizer nas práticas e discursos da justiça criminal: o tratamento judiciário dos "homicídios por auto de resistência" no Rio de Janeiro. 2012. 235 f. Dissertação (Mestrado em Direito). Universidade Federal do Rio de Janeiro. Rio de Janeiro, 2012.

LIMA, Igor Frederico Fontes de; REGINATO, Andréa Depieri de Albuquerque. A construção do inimigo como elemento de legitimação da militarização das polícias. 2016.

MISSE, Michel, GRILLO, Carolina Cristoph et al. Quando a polícia mata: homicídios por “autos de resisência" no Rio de Janeiro (2001-2011). Rio de Janeiro: NECVU; BOOKLINK, 2013.

PAVARINI, Massimo. Punir os Inimigos: criminalidade, exclusão e insegurança. Tradução de Juarez Cirino dos Santos e Aliana Cirino Simon. Curitiba: LedZe, 2012.

Revista de Criminologias e Políticas Criminais | e-ISSN: 2526-0065 | Curitiba | v. 2 | n. 2 | p. 1 - 15 | Jul/Dez. 2016. 
RODRIGUES, Luciana Boiteux de Figueiredo. Opinião Pública, política de drogas e repressão penal: uma visão crítica. In: BOKANY, Vilma. (Org.). Drogas no Brasil: entre a saúde e a justiça, proximidades e opiniões. 1ed. São Paulo: Fundação Perseu Abramo, 2015, v. 1, p. $143-158$.

WARAT, Luiz Alberto. Mitos e teorias na interpretação da lei. Porto Alegre: Editora Síntese Ltda, 1979, 159 p.

ZAFFARON, Eugenio Raúl. O inimigo no direito penal. Tradução de Sérgio Lamarão. 2. Ed. Rio de Janeiro: Revan, 2007. 224 p. 